\title{
Dynamic Non-Linear Enhancement using Gamma Correction and Dynamic Restoration
}

\author{
Parambir Singh \\ Amritsar College of Engg. \& Tech. \\ Amritsar, Punjab, India
}

\author{
Vijay Kumar Banga, Ph.D \\ Amritsar College of Engg. \& Tech. \\ Amritsar, Punjab, India
}

\begin{abstract}
This paper has proposed a new integrated image enhancement algorithm by integrating non linear image enhancement technique with dynamic restoration. Image processing plays a vital role in visualization application. It improves the visibility of poor images. Different techniques have been proposed so far. To improve image quality image enhancement can selectively enhance and restrain some information about image. It is a method which decreases image noise, eliminate artifacts, and maintain details. Its purpose is to amplify certain image features for analysis, diagnosis and display. The overall objective of this paper is to propose an integrated technique which will integrate the nonlinear enhancement technique with the gamma correction and dynamic restoration technique. The proposed algorithm is implemented in MATLAB. Experimental results have shown quite significant results over the available methods.
\end{abstract}

\section{Keywords}

Image enhancement, human visual perception, Visibility, Dynamic restoration, gamma correction

\section{INTRODUCTION}

In image processing, the process of improving the quality [2] of a digitally stored image by manipulating the image with certain methods. Advanced image enhancement techniques also support many filters for altering images in various ways. Programs specialized for image enhancements are sometimes called image digital image filters [5].

Image enhancement techniques acting as an important part in image processing. Somebody click image from common environment with elevated dynamic range include both dark and bright regions. Due to go outside in dynamic range of human eyes sensing, those image are not easy to distinguish by human eyes [7]. Image enhancement is a general approach to get enhanced quality of those images in terms of human visual observation. There are two techniques for image enhancement one is spatial domain and second is transform domain methods. In spatial domain method [9] an image is enhance by straight dealing with the intensity value in an image. In transform domain enhancement method it transforms the image intensity data into a specific domain by using different techniques like DFT, DCT, etc. Figure 1 is showing the poor visible input image. It is clearly shown in the image that it will not give much information to observers and, it may contain poor results for further processing.

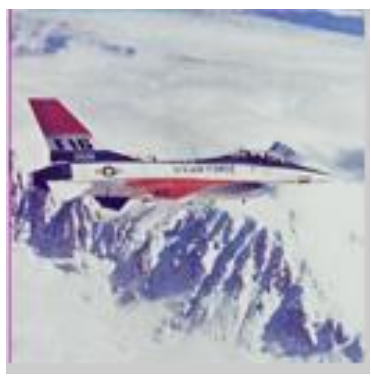

Figure 1. Input image [12]

Figure 2 is showing the enhanced image. It is clearly shown in the figure that all the objects are enhanced and image is now providing quite more information to the observers.

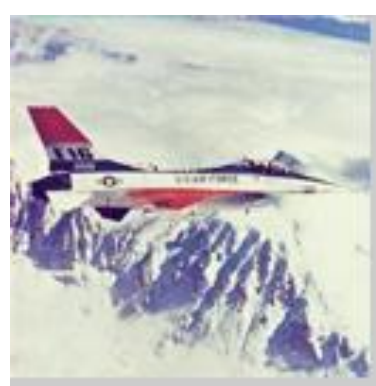

Figure 2. Enhanced Images [12]

Transform domain enhancement method engage mapping the image intensity data into a given transform domain by using transforms such as the 2-D discrete cosine transform (DCT). The main idea for using this technique is to improve the image quality by manipulating the transform coefficients. The main drawbacks of the transform-based image enhancement techniques are: they establish assured artifacts, they cannot concurrently enhance all pixels of the image properly and it is very hard to computerize the image enhancement procedure [9][6]. Color image enhancement plays a vital role in Digital Image Processing. The reason of image enhancement is to get better details of an image and highlight the helpful information. If a person takes an image by using a digital camera or mobile phone, in sunlight or dark room that image cannot be a good image. As a result of that image, it cannot be proper visualized for human eyes [13]. An image enhancement technique is generally used for the upgrading of the quality of a vague image. Among many image enhancement approaches, the nonlinear image enhancement (NIE) method has a simple structure and can obtain a good processing effect [14]. 


\section{IMAGE ENHANCEMENT TECHNIQUES}

The main objective of image enhancement is to improve some characteristic of an image to make it visually better one. Color image enhancement plays an important role in Digital Image Processing. The purpose of image enhancement is to get finer details of an image and highlight the useful information. If a person acquires an image by using a digital camera or mobile, the brightness such as glowing lamp in a room or sunlight in an open air is proper to be uneven and uncontrolled [13]

\subsection{Image Enhancement using HSV Color Space}

The color images are always represented in RGB color space. HSV space is nearer to human observation, the $(\mathrm{H})$ refers to the spectral composition of color, saturation (S) defines the clarity of colors and (V) refers the brightness of a color or just the luminance value of the color [9][13]. The following equations are shows the conversion of RGB values into HSV values.

$H= \begin{cases}H 1, & \text { if } B \leq G, \\ 360-H 1, & \text { if } B>G\end{cases}$

where,

$H 1=\cos ^{-1}\left\{\frac{0.5[(R-G)+(R-G)]}{\sqrt{(R-G)^{2}+(R-B)(G-B)}}\right\}$

$S=\frac{\max (R, G, B)-\min (R, G, B)}{\max (R, G, B)}$

$V=\frac{\max (R, G, B)}{255}$

The basic range of $(\mathrm{H})$ hue in equation is from 0 to 360 whereas saturation and values varies from 0 to 1 . The Image enhancement process includes remove artifacts, advanced color correction, filter adding and reduction, image replacement, augmentation and creation [11].

\subsection{Histogram Equalization}

Histogram equalization is a common method for enhancing the appearance of images. Histogram equalization is a method in image processing of contrast adjustment using the image's histogram. This process typically increases the universal contrast of many images, mainly when the usable data of the image is represented by close contrast values. Every level should hold the same number of pixel values [2].

\subsection{Contrast Enhancement}

The main use of contrast enhancement is to accomplish the image brightness. Contrast enhancement firstly divide the value component image in HSV image space into lesser overlapping blocks and find the shape of the nonlinear transfer function for every pixel. In contrast enhancement process, for each pixel the amount of enhancement is depending upon the midpoint pixel itself and its neighboring pixel values [10]. A neighboring pixel-dependent contrast enhancement method is used to achieve enough contrast, even elevated than original image [3].
After conducting the literature survey it has been found that the transform-based image enhancement introduces some inconsistencies like:-

- Transform-based image enhancement cannot enhance all parts of the image simultaneously and it is hard to automate the image enhancement process.

- The main drawback of transform based image enhancement is that, after enhancement the image detail are degraded.

\section{PROBLEM FORMULATION}

In order to reduce the problems of the limitations of the exiting techniques a new hybrid non linear image enhancement technique is proposed. Proposed technique will integrate non-linear enhancement technique with image restoration. The proposed algorithm is seems to be significant as the transform-based image enhancement methods results in certain artifacts on the output enhanced image, so restoration technique will reduce these artifacts. The proposed algorithm will use HSV plane to enhance the image, as it is known $\mathrm{H}$ and $\mathrm{S}$ component need no modification for enhancement so alteration will be done on $\mathrm{V}$ (intensity) only.

The proposed method comprises three processes, i.e. adaptive intensity enhancement, contrast enhancement and color restoration. Adaptive intensity enhancement utilizes a particularly designed nonlinear transfer function which is proficient of reducing the intensity of light regions and at the same time enhancing the intensity of gloomy regions. Contrast enhancement tunes the intensity of each pixels magnitude based on its nearby pixels. Finally, color restoration process based on the chromatic information of the input image frame is applied to convert the enhanced intensity image back to a color image.

\section{PROPOSED TECHNIQUE}

The main objective of algorithm which will provide better results than existing algorithms to enhance the images. Dynamic image restoration using adaptive gamma correction and also adaptive smoothing technique will be integrated to the non linear enhancement method to provide more accurate results. By doing this we can hope that the detailed variance and background variance will be increased and decreased respectively. However dynamic restoration may come up with some potential overheads so we will try to reduce them. Figure 3 is showing the various steps to achieve the objectives.

Step 1: In step 1 image is passed to the system and some pre-processing operations are applied on it.

Step 2: In step 2 images is converted in HSV plane.

Step 3: As $\mathrm{H}$ and $\mathrm{S}$ component stay constant but $\mathrm{V}$ is the only factors which need some alteration while enhancing the images.

Step 4: Now overlapped window based local processing for dynamic range compression will be applied on $\mathrm{V}$ component.

Step 5: Now pixel neighborhood based contrast enhancement is applied on the image.

Step 6: Now re-convert given image to HSV to RGB again.

Step 7: Now apply dynamic restoration algorithm.

Step 8: Get output image. 


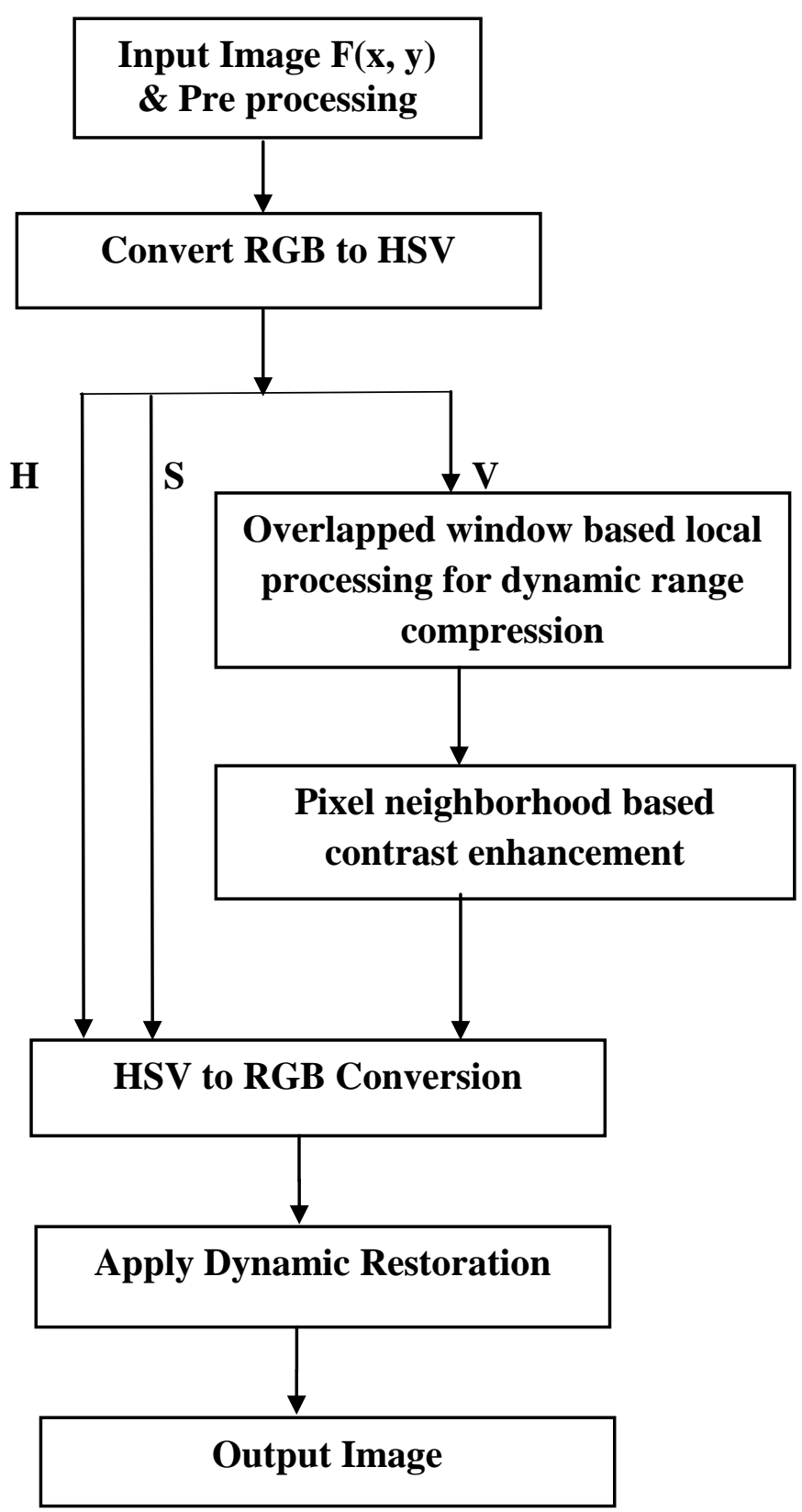

Figure 3. Proposed Algorithm

\section{EXPERIMENTAL SET-UP}

In order to implement the proposed algorithm; design and implementation has been done in MATLAB using image processing toolbox. In order to do cross validation we have also implement the histogram equalization and nonlinear enhancement technique. Table 1 is showing the various images which are used in this research work. Images are given along with their formats. All the images are of different kind and each image has different kind of the light i.e. more or less in some images.
Table 1. Experimental images

\begin{tabular}{|l|l|l|}
\hline Sr.No. & NAME & FORMAT \\
\hline 1 & image1 & jpg \\
\hline 2 & image2 & jpg \\
\hline 3 & image3 & jpg \\
\hline 4 & image4 & jpg \\
\hline 5 & image5 & jpg \\
\hline 6 & image6 & jpg \\
\hline 7 & image7 & jpg \\
\hline 8 & image8 & jpg \\
\hline 9 & image9 & jpg \\
\hline 10 & image10 & jpg \\
\hline 11 & image11 & jpg \\
\hline 12 & image12 & jpg \\
\hline 13 & image13 & jpg \\
\hline 14 & image14 & jpg \\
\hline 15 & image15 & jpg \\
\hline 16 & image16 & jpg \\
\hline
\end{tabular}

\section{EXPERIMENTAL RESULTS}

For the purpose of cross validation we have taken 16 different images and passed to the histogram equalization, non-linear enhancement and proposed algorithm. Subsequent section contains a result of one of the 16 selected images to show the improvisation of the proposed algorithm over the other techniques.

Figure 4 has shown the input image for experimental purpose. The image has low brightness and some more effect of the green color. The overall objective is to improve the brightness of the image and also reduce the effect of the green channel.

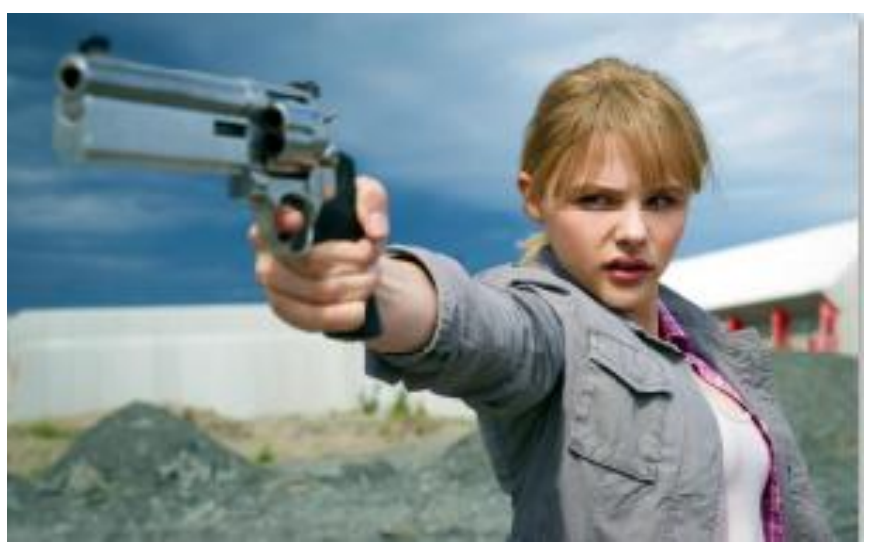

Figure 4. Input image

Figure 5 has shown the output image taken by the histogram equalization. However the problem of this technique is found to be some artifacts which have degrades the quality of the image. 


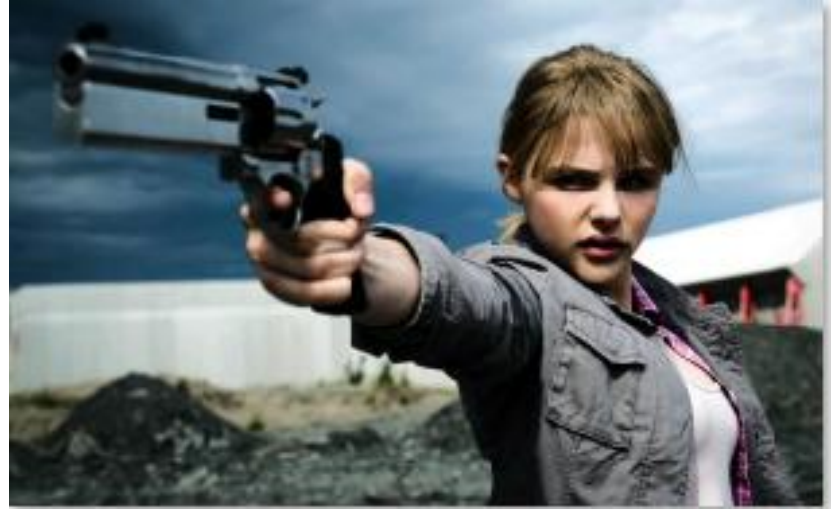

Figure 5. Histogram equalization

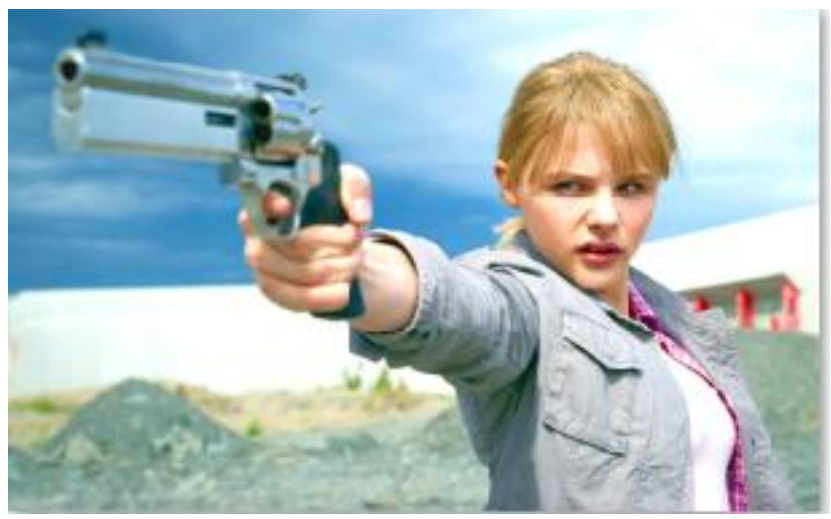

Figure 6.Nonlinear enhanced image

Figure 6 has shown the output image taken by the nonlinear color image enhancement technique. The image has contained too much brightness and some more effect of the green color. However the problem of this technique is found to be is the effect of the green channel has not been minimized as expected.

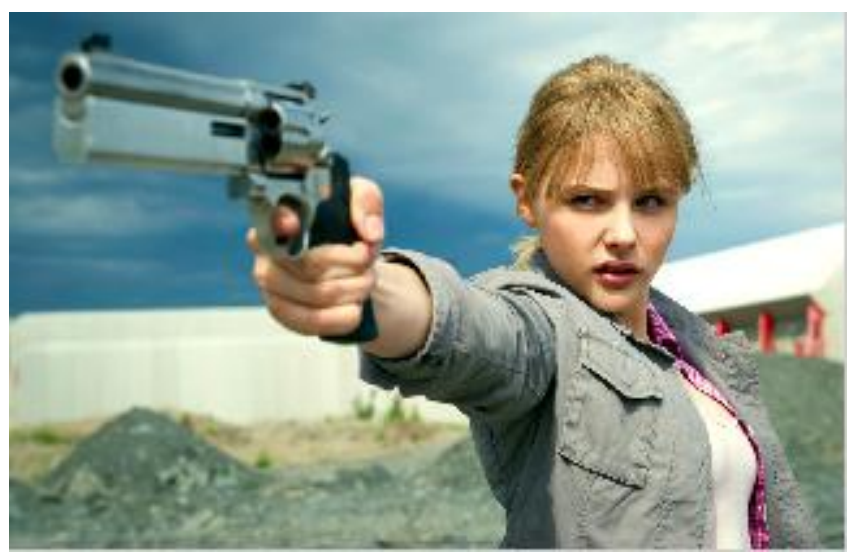

Figure 7. Integrated nonlinear enhanced image with gamma correction

Figure 7 has shown the output image taken by the integrated technique of the gamma correction with nonlinear enhancement. The image has contained too much brightness but still has more effect of the brown color.

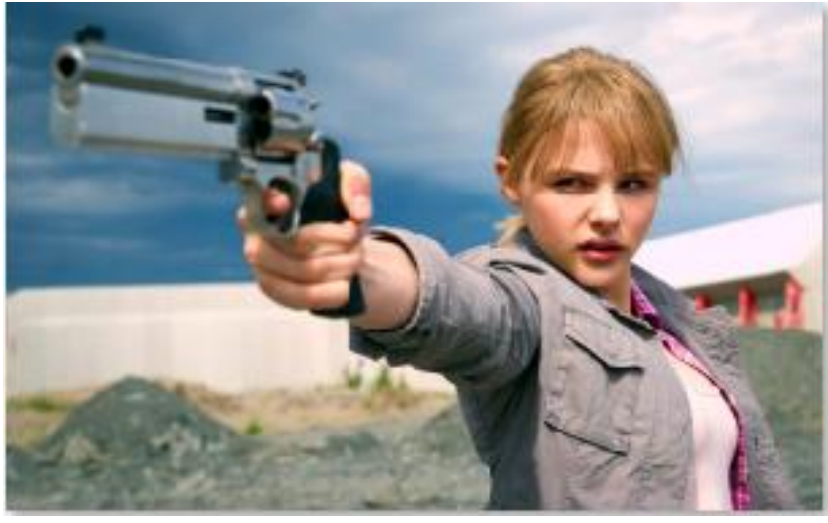

Figure 8.Final proposed image

Figure 8 has shown the output image taken by the integrated technique of the gamma correction, dynamic restoration with nonlinear enhancement. The image has contained the balanced brightness and the effect of the green channel is also reduced. Comparing with other method the proposed has shown quite significant result with respect to all cases. The effect of the individual channel has also been normalized as well as the effect of the brightness is also normalized.

\section{PERFORMANCE ANALYSIS}

This section contains the cross validation between existing and proposed techniques. Some well-known image performance parameters for digital images have been selected to prove that the performance of the proposed algorithm is quite better than the available methods..

Table 2. Mean Square Error

\begin{tabular}{|l|l|l|l|}
\hline $\begin{array}{l}\text { Image } \\
\text { Name }\end{array}$ & $\begin{array}{l}\text { Histogram } \\
\text { Equ. }\end{array}$ & $\begin{array}{l}\text { Old } \\
\text { Technique }\end{array}$ & $\begin{array}{l}\text { Proposed } \\
\text { Algorithm }\end{array}$ \\
\hline Img1 & 39039 & 1322 & 854 \\
\hline Img2 & 12338 & 1302 & 1079 \\
\hline Img3 & 15031 & 1040 & 675 \\
\hline Img4 & 12466 & 1395 & 612 \\
\hline Img5 & 34256 & 1340 & 603 \\
\hline Img6 & 20359 & 1628 & 399 \\
\hline Img7 & 33411 & 1317 & 293 \\
\hline Img8 & 34822 & 967 & 240 \\
\hline Img9 & 27696 & 2277 & 204 \\
\hline Img10 & 16573 & 1435 & 195 \\
\hline Img11 & 13062 & 1907 & 169 \\
\hline Img12 & 19271 & 1415 & 174 \\
\hline Img13 & 56618 & 404 & 155 \\
\hline Img14 & 33158 & 1968 & 246 \\
\hline Img15 & 10471 & 1269 & 118 \\
\hline Img16 & 34409 & 2032 & 116 \\
\hline
\end{tabular}

Table 2 has shown the quantized analysis of the mean square error. As mean square error need to be reduced therefore the proposed algorithm is showing the better results than the available methods as mean square error is less in every case

Table 3 is showing the comparative analysis of the Peak Signal to Noise Ratio (PSNR). As PSNR need to be maximized; so the main goal is to increase the PSNR as much as possible. Table 3 has clearly shown that the PSNR is maximum in the case of the proposed algorithm therefore proposed algorithm is providing better results than the available methods. 
Table 3. Peak Signal -to- Noise Ratio

\begin{tabular}{|l|l|l|l|}
\hline $\begin{array}{l}\text { Image } \\
\text { Name }\end{array}$ & $\begin{array}{l}\text { Histogram } \\
\text { Equ. }\end{array}$ & $\begin{array}{l}\text { Old } \\
\text { Technique }\end{array}$ & $\begin{array}{l}\text { Proposed } \\
\text { Algorithm }\end{array}$ \\
\hline Img1 & 2.8110 & 16.9185 & 18.8162 \\
\hline Img2 & 7.2184 & 16.9847 & 17.8006 \\
\hline Img3 & 6.3609 & 17.9605 & 19.8378 \\
\hline Img4 & 7.1735 & 16.6851 & 20.2633 \\
\hline Img5 & 2.7834 & 16.8598 & 20.3276 \\
\hline Img6 & 5.0432 & 16.0143 & 22.1211 \\
\hline Img7 & 2.8919 & 16.9349 & 23.4621 \\
\hline Img8 & 2.7123 & 18.2765 & 24.3287 \\
\hline Img9 & 3.7066 & 14.5572 & 25.0345 \\
\hline Img10 & 5.9368 & 16.5623 & 25.2303 \\
\hline Img11 & 6.9707 & 15.3273 & 25.8519 \\
\hline Img12 & 5.2818 & 16.6232 & 25.7253 \\
\hline Img13 & 0.6013 & 22.0670 & 26.2275 \\
\hline Img14 & 2.9249 & 15.1906 & 24.2215 \\
\hline Img15 & 7.9309 & 17.0962 & 27.4120 \\
\hline Img16 & 2.7641 & 15.0516 & 27.4862 \\
\hline
\end{tabular}

Table 4 is showing the comparative analysis of the Maximum Difference. As Maximum Difference needs to be minimized; so the main objective is to reduce them Maximum Difference as much as possible. Table 4 has clearly shown that Maximum Difference is less in our case therefore the proposed algorithm has shown significant results over the proposed algorithm.

Table 4. Maximum Difference

\begin{tabular}{|l|l|l|l|}
\hline $\begin{array}{l}\text { Image } \\
\text { Name }\end{array}$ & $\begin{array}{l}\text { Histogram } \\
\text { Equ. }\end{array}$ & $\begin{array}{l}\text { Old } \\
\text { Technique }\end{array}$ & $\begin{array}{l}\text { Proposed } \\
\text { Algorithm }\end{array}$ \\
\hline Img1 & 254 & 9 & 3 \\
\hline Img2 & 254 & 18 & 3 \\
\hline Img3 & 254 & 52 & 3 \\
\hline Img4 & 204 & 28 & 3 \\
\hline Img5 & 254 & 23 & 2 \\
\hline Img6 & 254 & 40 & 3 \\
\hline Img7 & 254 & 75 & 0 \\
\hline Img8 & 254 & 43 & 3 \\
\hline Img9 & 219.0598 & -13 & 0 \\
\hline Img10 & 254 & 26 & 3 \\
\hline Img11 & 254 & 17 & 3 \\
\hline Img12 & 254 & 31 & 3 \\
\hline Img13 & 254 & 20 & 3 \\
\hline Img14 & 254 & 3 & 1 \\
\hline Img15 & 254 & 27 & 3 \\
\hline Img16 & 254 & 0 & 7 \\
\hline
\end{tabular}

Table 5 is showing the comparative analysis of the Maximum Difference. Mean Difference contains the average difference between input and output image. Table 5 has clearly demonstrated that the Mean Difference is quite less in the case of the proposed algorithm; therefore proposed algorithm is providing better results.

Table 5. Mean Difference

\begin{tabular}{|l|l|l|l|}
\hline $\begin{array}{l}\text { Image } \\
\text { Name }\end{array}$ & $\begin{array}{l}\text { Histogram } \\
\text { Equ. }\end{array}$ & $\begin{array}{l}\text { Old } \\
\text { Technique }\end{array}$ & $\begin{array}{l}\text { Proposed } \\
\text { Algorithm }\end{array}$ \\
\hline Img1 & 176.2400 & 35.4839 & 27.6155 \\
\hline Img2 & 95.3807 & 33.7947 & 27.7507 \\
\hline Img3 & 98.4194 & 26.4427 & 20.5744 \\
\hline Img4 & 104.6390 & 36.9264 & 22.7708 \\
\hline Img5 & 178.4211 & 34.6758 & 23.4465 \\
\hline Img6 & 130.2392 & 38.5495 & 17.7392 \\
\hline Img7 & 173.8735 & 33.7769 & 15.9162 \\
\hline Img8 & 160.3133 & 24.7230 & 11.3477 \\
\hline
\end{tabular}

\begin{tabular}{|l|l|l|l|}
\hline Img9 & 158.7783 & 47.2256 & 13.3805 \\
\hline Img10 & 101.9914 & 35.9558 & 10.1576 \\
\hline Img11 & 97.2257 & 43.1009 & 10.2456 \\
\hline Img12 & 114.7699 & 34.2727 & 10.1654 \\
\hline Img13 & 237.4300 & 16.1787 & 10.2520 \\
\hline Img14 & 177.0887 & 43.3806 & 15.0889 \\
\hline Img15 & 71.6922 & 32.5905 & 6.6922 \\
\hline Img16 & 181.1426 & 41.8341 & 9.3163 \\
\hline
\end{tabular}

Table 6 is showing the comparative analysis of the Background Variance (BV) and Detailed Variance (DV). As background detail need to be reduced because human eyes does not focus on the background detail of the image. The table 6 has clearly shown that BV is less for most of the images therefore proposed algorithm is better in more cases. The Detailed Variance (DV) need to be maximized as human eyes focuses on the same. The table 6 has shown quite better DV than the available methods.

Table 6. BV and DV values for different enhancement methods

\begin{tabular}{|l|l|l|l|l|l|l|}
\hline \multirow{2}{*}{$\begin{array}{l}\text { Image } \\
\text { Name }\end{array}$} & \multicolumn{2}{l|}{$\begin{array}{l}\text { Histogram } \\
\text { Equ. }\end{array}$} & \multicolumn{2}{l|}{ Old Technique } & \multicolumn{2}{l|}{$\begin{array}{l}\text { Proposed } \\
\text { Algorithm }\end{array}$} \\
\cline { 2 - 7 } & BV & DV & BV & DV & BV & DV \\
\hline Img1 & 0.147 & 13.579 & 0.096 & 20.761 & 0.074 & 27.040 \\
\hline Img2 & 0.151 & 13.209 & 0.099 & 20.189 & 0.080 & 24.870 \\
\hline Img3 & 0.074 & 25.838 & 0.091 & 21.828 & 0.074 & 27.003 \\
\hline Img4 & 0.159 & 12.513 & 0.094 & 21.236 & 0.069 & 28.748 \\
\hline Img5 & 0.127 & 15.720 & 0.093 & 21.297 & 0.088 & 22.567 \\
\hline Img6 & 0.122 & 16.389 & 0.090 & 22.162 & 0.074 & 26.818 \\
\hline Img7 & 0.186 & 10.708 & 0.094 & 21.232 & 0.100 & 19.991 \\
\hline Img8 & 0.097 & 20.469 & 0.084 & 23.752 & 0.075 & 26.500 \\
\hline Img9 & NaN & NaN & 0.093 & 21.399 & 0.054 & 36.646 \\
\hline Img10 & 0.144 & 13.834 & 0.088 & 22.606 & 0.096 & 23.251 \\
\hline Img11 & 0.176 & 11.335 & 0.975 & 20.891 & 0.094 & 21.151 \\
\hline Img12 & 0.152 & 13.157 & 0.092 & 21.740 & 0.091 & 21.832 \\
\hline Img13 & 0.109 & 18.233 & 0.094 & 21.257 & 0.053 & 37.104 \\
\hline Img14 & 0.136 & 14.609 & 0.088 & 22.658 & 0.084 & 23.770 \\
\hline Img15 & 0.097 & 20.547 & 0.106 & 18.851 & 0.053 & 37.293 \\
\hline Img16 & NaN & NaN & 0.095 & 20.950 & 0.084 & 23.621 \\
\hline
\end{tabular}

Figure 9 has shown the quantized analysis of the mean square error. As mean square error need to be reduced therefore the proposed algorithm is showing the better results than the available methods as mean square error is less in every case. 


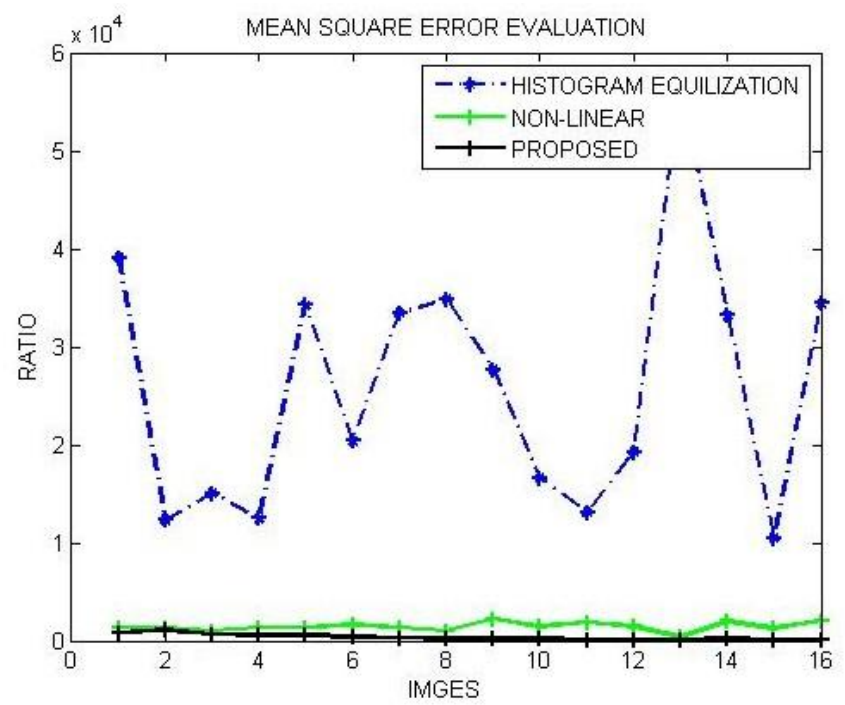

Figure 9.Mean Square Error

Figure 10 is showing the comparative analysis of the Peak Signal to Noise Ratio (PSNR). As PSNR need to be maximized; so the main goal is to increase the PSNR as much as possible. Figure 10 has clearly shown that the PSNR is maximum in the case of the proposed algorithm therefore proposed algorithm is providing better results than the available methods.

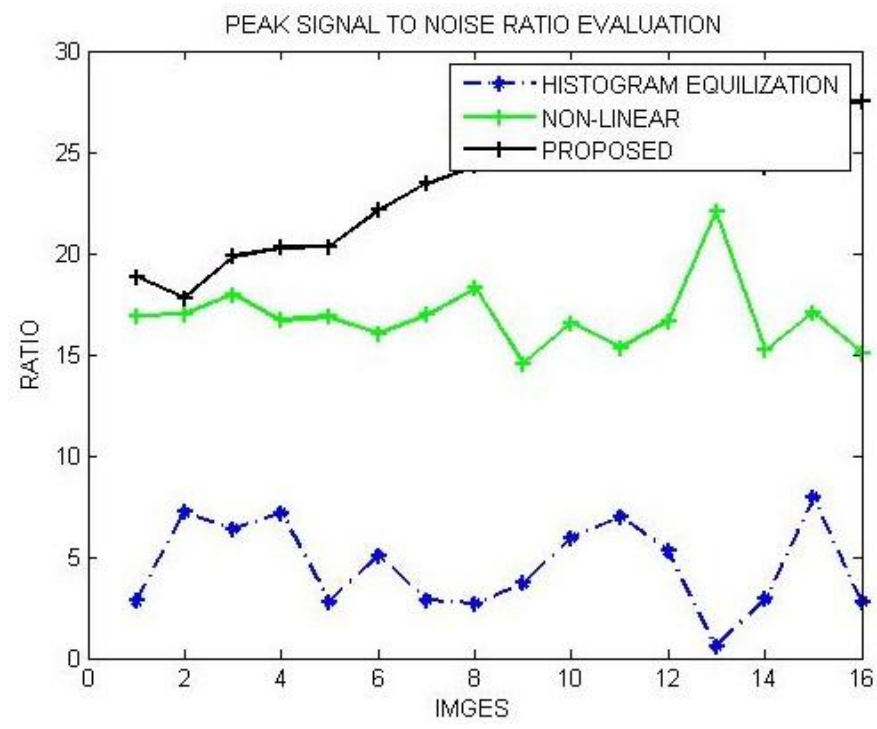

Figure 10.Peak Signal -to- Noise Ratio

Figure 11 is showing the comparative analysis of the Maximum Difference. As Maximum Difference needs to be minimized; so the main objective is to reduce them Maximum Difference as much as possible. Figure 11 has clearly shown that Maximum Difference is less in our case therefore the proposed algorithm has shown significant results over the proposed algorithm.

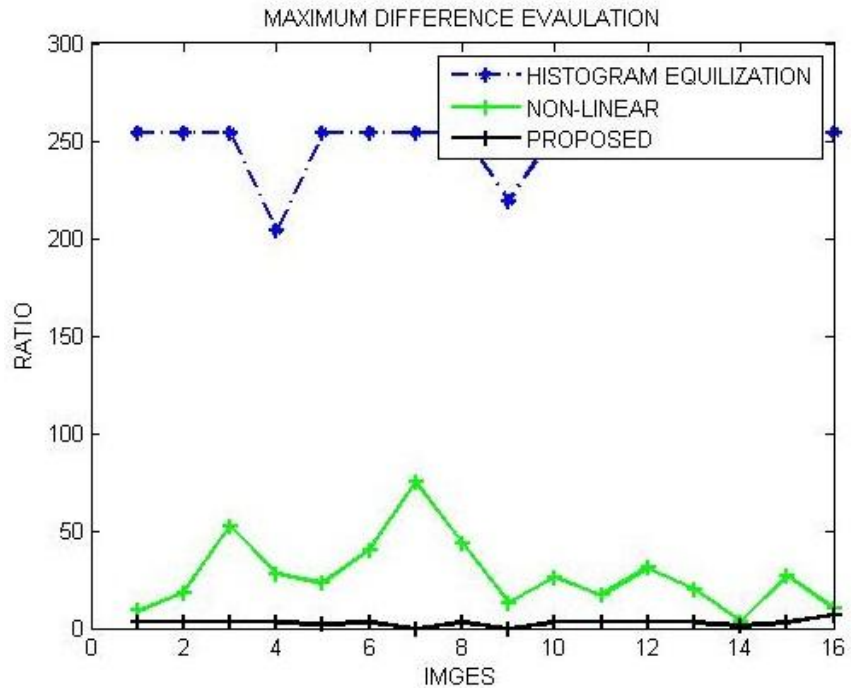

Figure 11. Maximum Difference

Figure 12 is showing the comparative analysis of the Maximum Difference. Mean Difference contains the average difference between input and output image. Figure 12 has clearly demonstrated that the Mean Difference is quite less in the case of the proposed algorithm; therefore proposed algorithm is providing better results.

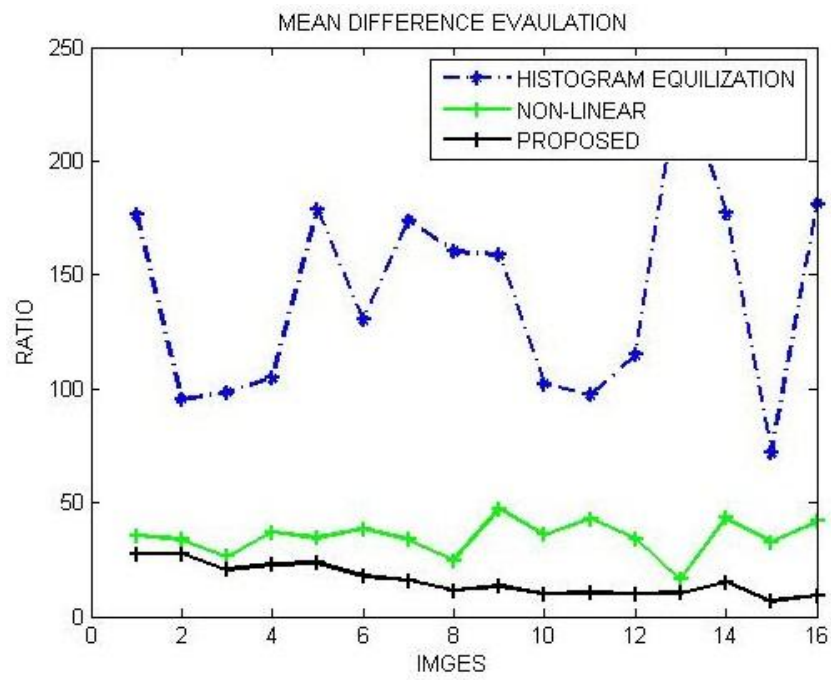

Figure 12. Mean Difference

Figure 13 and 14 is showing the comparative analysis of the Background Variance (BV) and Detailed Variance (DV). As background detail need to be reduced because human eyes does not focus on the background detail of the image. The Figure 13 has clearly shown that $\mathrm{BV}$ is less for most of the images therefore proposed algorithm is better in more cases. The Detailed Variance (DV) need to be maximized as human eyes focuses on the same. The Figure 14 has shown quite better DV than the available methods. 


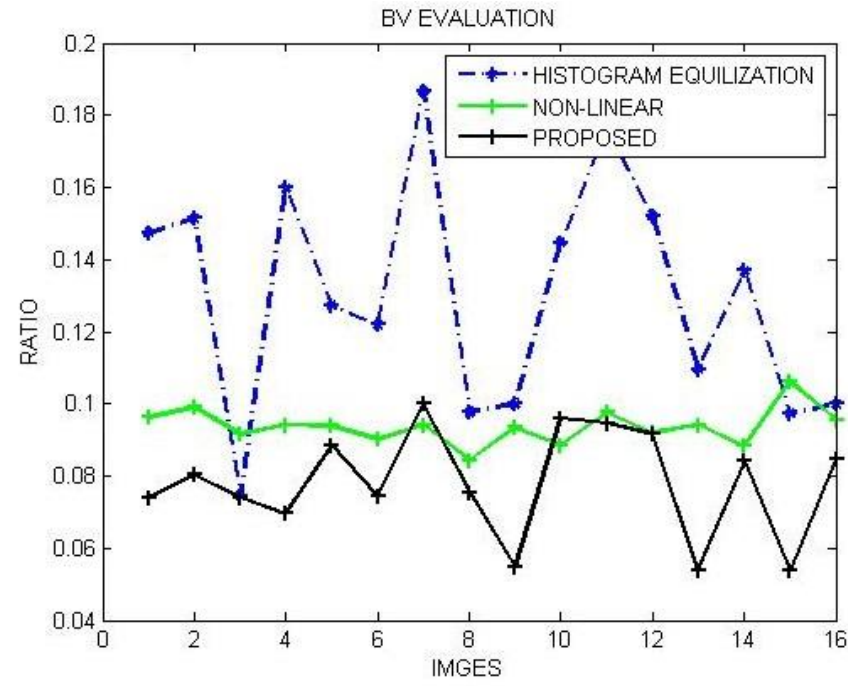

Figure 13.Background Variance

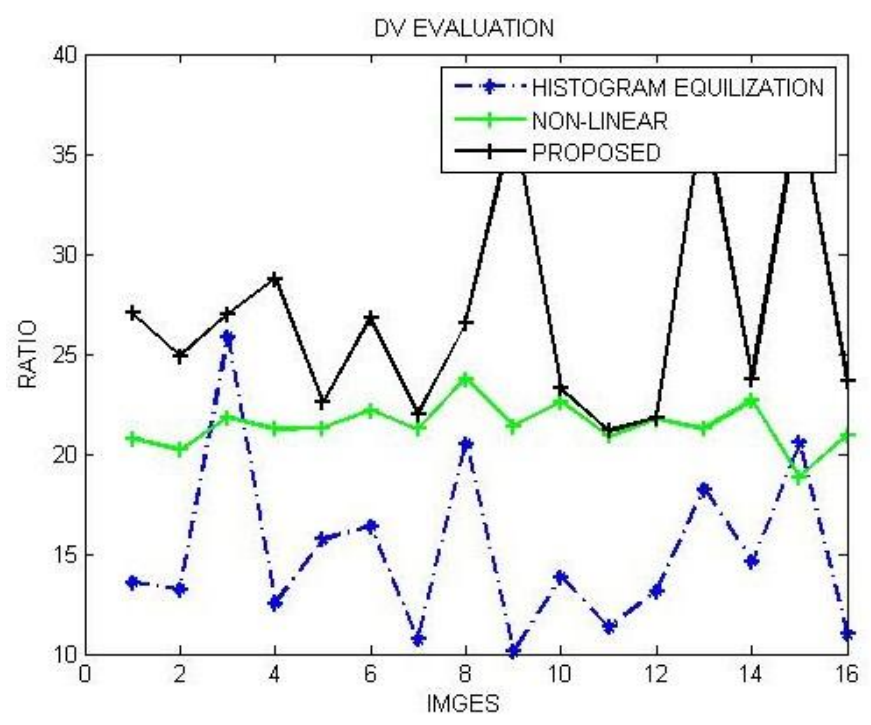

Figure 14.Detailed Variance

\section{CONCLUSION AND FUTURE WORK}

The image enhancements techniques play a significant role in digital image processing. It is shown in this paper that the nonlinear image enhancement can be used to improve the quality of a blurred image by using the concept of the light source refinement. This work has proposed an integrated enhancement algorithm to improve the detailed variance in images. The proposed solution has been designed and implemented in MATLAB using image processing toolbox. Different 50 images have been taken for experimental purpose and it is found that in most of cases the proposed algorithm provides better results. The performance evaluation has shown that the proposed algorithm provides slightly significant results over the available methods.

In near future we will use adaptive gradient smoothing will be used to provide more better and accurate results. However no filtering technique is used in this research work; so in near future some efficient filtering technique will also be used.

\section{REFERENCES}

[1] Crespo, J. , Maojo, V. ; Herrero, C. ; Sanandres, J.A, "Enhancement of MR images using non-linear techniques" 18th Annual International Conference of the IEEE Engineering in Medicine and Biology Society, Amsterdam, pp. 752-753, Nov. 1996.

[2] Y. T. Kim, "Contrast enhancement using brightness preserving bi- histogram equalization", IEEE Transactions on Consumer Electronics Suwon, Korea Vol. 43, pp.1- 8, Feb. 1997.

[3] Arigela, Saibabu, and K. Vijayan Asari. "An Adaptive and Non Linear Technique for Enhancement of Extremely High Contrast Images." $35^{\text {th }}$ IEEE Applied Imagery and Pattern Recognition Workshop, Norfolk, Virginia, USA. pp. 24-24, April 2006.

[4] Lung-Jen Wang, Ya-Chun Huang "An Improved NonLinear Image Enhancement Method for Video Coding" International Conference on Complex, Intelligent and Software Intensive Systems in Barcelona Spain, pp. 7984, March 2008.

[5] Unaldi, N., Temel, S. ; Asari, V.K. ; Rahman, Z.-u. "An automatic wavelet-based nonlinear image enhancement technique for aerial imagery" 4th International Conference on Recent Advance in Space Technology, Istanbul ,Turkey, pp. 307-312, June 2009.

[6] Hossain, Md Foisal, Mohammad Reza Alsharif, and Katsumi Yamashita. "Medical image enhancement based on nonlinear technique and logarithmic transform coefficient histogram matching.", 2010 IEEE/ICME International Conference on Complex Medical Engineering (CME), Gold Coast, Australia pp. 58-62. July, 2010.

[7] Lung-Jen Wang, Ya-Chun Huang, "Non-Linear Image Enhancement Using Opportunity Costs" Second International Conference on Computational Intelligence, Communication Systems and Networks, Liverpool, pp. 256-261, July 2010.

[8] Xizhen Han , Zhao Jian "A nonlinear image enhancement algorithm based on partial differential equations", IEEE 10th International Conference on Signal Processing (ICSP), in Beijing China Oct. 2010.

[9] Deepak Ghimire, Joonwhoan Lee, "Nonlinear Transfer Function-Based Local Approach for Color Image Enhancement", IEEE Transactions on Consumer Electronics, Vol. 57, issue. 2, , pp. 858-865 May 2011.

[10] Ullah, I., and S. H. Amin. "Application of image enhancement techniques for shape reconstruction using shape from shading." IEEE International Conference on Computer Networks and Information Technology (ICCNIT), Peshawar Campus, Pakistan, pp. 315-318, July 2011.

[11] Lizhu Liu, Haiying Wang, "Image Enhancement Using a Nonlinear Method with an Improved Single-Scale Retinex Algorithm" International Conference on Electronics, Communications and Control (ICECC), Ningbo China, pp. 2086-2089, Sept. 2011. Sept. 2011.

[12] Murahira, Kota, and Akira Taguchi. "Hue-Preserving Color Image Enhancement in RGB Color Space with Rich Saturation. "IEEE International Symposium on Intelligent Signal Processing and Communication 
Systems (ISPACS) in New Taipei Taiwan. pp 266-269, Nov. 2012.

[13] Vishwakarma, Anish Kumar, Agya Mishra, Kumar Gaurav, and Abhishek Katariya. "Illumination Reduction for Low Contrast Color Image Enhancement with Homomorphic Filtering Technique." IEEE International Conference on Communication Systems and Network Technologies (CSNT), Rajkot, Gujarat, India, pp. 171173, May 2012.

[14] Wang, Lung-Jen, and Ya-Chun Huang. "Combined Opportunity Cost and Image Classification for Non-
Linear Image Enhancement." IEEE Sixth International Conference on Complex, Intelligent and Software Intensive Systems (CISIS), Palermo, Italy, pp. 135-140. July 2012

[15] Sunanda. S Alur and M. C Hanumantharaju, "A Novel Approach Based On wavelet and Non-Linear Transfer Function-Based Local Approach for Real Color Image Enhancement", IEEE International Conference on Computing Sciences, Punjab, India pp. 1-6, September 2012. 